Article

\title{
Increased Internal Porosity and Surface Area of Hydroxyapatite Accelerates Healing and Compensates for Low Bone Marrow Mesenchymal Stem Cell Concentrations in Critically-Sized Bone Defects
}

\author{
Eileen R. Dawson ${ }^{1,2}$, Richard K. Suzuki ${ }^{2}$, Melissa A. Samano ${ }^{1,2}$ and Matthew B. Murphy ${ }^{1,2,3, *}$ \\ 1 Department of Biomedical Engineering, The University of Texas at Austin, Austin, TX 78705, USA; \\ eileen.dawson@gmail.com (E.R.D.); melissa.samano@utexas.edu (M.A.S.) \\ 2 Celling Biosciences, Austin, TX 78701, USA; RichardKSuzuki@gmail.com \\ 3 Murphy Lifescience Consulting, Austin, TX 78702, USA \\ * Correspondence: mbmurphy@utexas.edu
}

Received: 6 July 2018; Accepted: 6 August 2018; Published: 14 August 2018

Featured Application: Volume and rate of tissue regeneration may be enhanced with increased scaffold porosity as well as increased numbers of non-cultured bone marrow cells.

\begin{abstract}
For clinical treatment of skeletal defects, osteoinductive scaffolds must have the ability to conform to the unique geometry of the injury site without sacrificing biologically favorable properties, including porosity. This investigation seeks to combine the osteoinductive properties of porous hydroxyapatite (HA) scaffolds with the beneficial handling characteristics of granules or putties, while evaluating the effects of mesenchymal stem cell (MSC) concentration on the composite grafts' ability to regenerate bone in vivo. The results demonstrate that porous HA granules regenerate significantly larger volumes of bone compared to non-porous HA. Increased MSC concentrations in autologous bone marrow aspirate (BMA) contributed to greater bone regeneration. This effect was most predominant with non-porous HA. While the extent of bone regeneration using non-porous HA was strongly correlated with MSC concentration of the marrow, porous HA microparticles combined with autologous BMA were successful in faster treatment of critically-sized bone defects and with less dependence on the MSC concentration than non-porous HA.
\end{abstract}

Keywords: hydroxyapatite; biomaterial porosity; mesenchymal stem cell; bone marrow aspirate; bone regeneration

\section{Introduction}

Critically-sized bone defects arise from traumatic injury, tumor resection, autologous bone graft harvesting, and surgical procedures, including spinal fusion. Autografts, considered the gold standard in bone substitutes, are impractical for use in larger defects, as graft size would be limited to patient sample availability. Additionally, pain and local donor site morbidity are commonly reported at the site of graft harvesting [1]. Nonetheless, autografts are successful in defect treatment because they combine a number of key components necessary for tissue growth. Bone regeneration requires contributions from all aspects of the "tissue engineering paradigm", including progenitor cells, which are a scaffold to guide tissue formation and remodeling, and biochemical/biomechanical stimuli.

Significant research has investigated various biomaterials and scaffolding techniques with osteoconductive or osteoinductive properties. Among these biomaterials is hydroxyapatite (HA), 
the primary crystalized form of calcium phosphate comprising the inorganic portion of bones, which has consistently demonstrated the ability to promote bone growth in vivo [2,3]. Monolithic scaffolds are commonly utilized, usually conforming to the pre-determined geometry of controlled defects created in animal models [4,5]. In clinical application, this type of scaffold would be impractical. The implanted scaffold must span the full volume of the defect-thus, having a pre-sized scaffold would limit its application to defects of specific sizes, or require the physician to modify the graft or the graft site. Graft modification requires costly operating-room time and introduces the risk of damaging the biomaterial. Graft site modification could have deleterious effects to the patient, in that use of a reamer or burr causes heat generation and local tissue necrosis. Ultimately, a moldable formulation may reduce time in surgery and avoid additional bone loss or trauma to the surrounding tissue area [6]. It would therefore be advantageous for the scaffolding material to be moldable to irregular geometries presented in most clinical cases to completely fill the defect and bridge the native bone. There are, however, a number of physical characteristics of bone grafts that need to be retained. The inclusion of porosity in the HA scaffolds cannot be understated, as there is typically a correlation between the extent and interconnectivity of pores and the scaffold's ability to regenerate bone [7-10]. Interconnected porosity encourages the in vivo infiltration of autologous cells and vasculature. High porosity may be achieved with ceramics by employing a granular or microparticle preparation. This approach has been validated in limited studies without specific tailoring of granule porosity or surface area, nor thorough characterization of the cellular component of the graft [11-13].

The contribution of cells is often overlooked in biomaterials-based approaches for orthopedic healing. However, it is ultimately the cells, whether they be transplanted with the graft or recruited endogenously, that are responsible for new tissue generation and remodeling [14,15]. We recently reported that many Food and Drug Administration (FDA)-cleared or approved biomaterials for bone healing are not efficient at retaining bone marrow-derived cells and, in many instances, were cytotoxic, with $\mathrm{pH}$ values less than 7 or greater than 10 when reconstituted in plasma or saline [16]. Materials that were not easily soluble (allograft bone and calcium phosphates) were most successful at retaining bone marrow mesenchymal stem or stromal cells (MSCs) and inducing osteogenic gene expression in an in vitro simulation of surgical graft preparation. In addition to the effects of materials on cells, the source and number of cells must be considered. Many in vivo studies combine biomaterials with culture-expanded autologous or allogeneic cells as an implantable graft. Although this is convenient to standardize "doses" of therapeutic agents and seemingly control one variable of the regenerative paradigm, researchers often fail to recognize the inherent variability of cell potency from donor to donor, the effects of culture conditions/passage number, or the value of a heterogenous population, including multiple progenitor phenotypes (mesenchymal, hematopoietic, endothelial, etc.). The clinical translation of an in vitro expanded cell approach is further in question due to regulatory restrictions of the United States FDA and other agencies. The usage of autologous cells at the point-of-care is an appealing alternative, with less regulatory requirements and a decreased risk of cell contamination or rejection. A growing amount of data has suggested strong correlations in clinical outcomes with non-union fracture, degenerative disc disease, rotator cuff tear, avascular necrosis, and other orthopedic injuries, based on the concentration of MSCs present in bone marrow at physiological levels, or concentrated up to 10× [17-19]. The effects of non-cultured MSC concentration on bone formation when combined with HA granular particles are presently unreported in the literature.

In the present study, we investigated the combination of autologous bone marrow aspirate with porous or non-porous HA granules. Both of these materials were prepared with a collagen-derived carrier to quickly absorb the bone marrow and form a moldable putty, to pack into bilateral, critically-sized femoral chondyle defects in adult rabbits. An aliquot of each animal's bone marrow was evaluated for nucleated cell concentration and MSC content to retrospectively examine the effects of MSC concentration in fresh marrow, as well as the effects of granular porosity with identical cell populations in the same animal. 


\section{Materials and Methods}

\subsection{Implant Materials}

Non-porous (Nanoss ${ }^{\circledR}$ Bioactive, Pioneer Surgical, Marquette, MI, USA) and porous (Solum IV, Celling Biosciences, Austin, TX, USA) HA particles are a combination of sintered nanocrystalline ( $<500 \mathrm{~nm}) \mathrm{HA}$ and a collagen-derived carrier, and have been cleared by the FDA for use as a bone void filler. The HA granules' diameters were in the range of 400-2000 $\mu \mathrm{m}$. Porous HA granules featured $90 \%$ porosity with an average macroporosity (interconnected pore diameter) of $300 \pm 100 \mu \mathrm{m}$, and a microporosity (internal surface pore diameter) of $25 \pm 10 \mu \mathrm{m}$. Both materials were characterized for average pore size and pore interconnectivity by scanning electron microscopy (Figure 1).

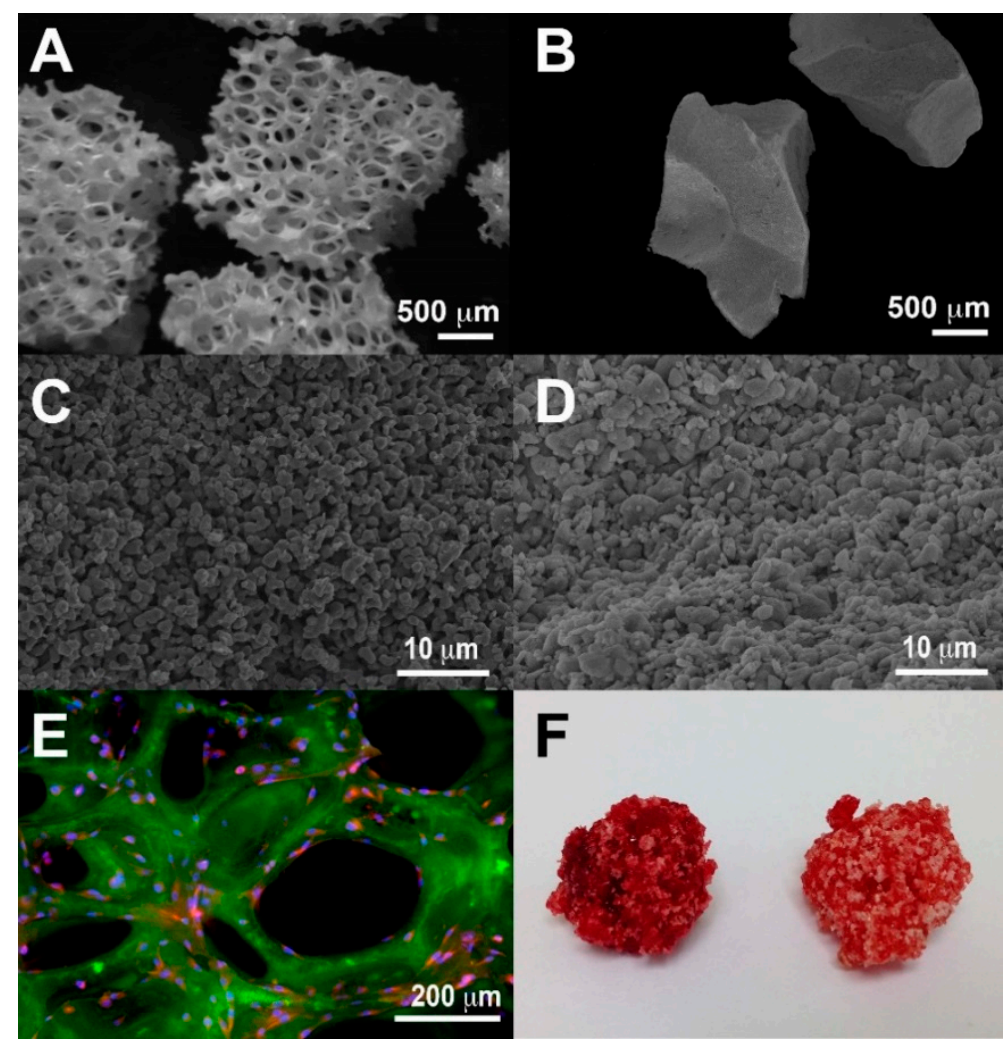

Figure 1. Porous hydroxyapatite (HA) granules (A) present significantly greater surface area per volume than traditional, non-porous microparticles (B); while the surface topography based on the 500-800 nm size of pre-sintered HA particles is similar for the porous (C) and non-porous (D) granules. (E) Mesenchymal cells proliferate throughout the porous HA scaffold in vitro observed by staining for nuclei (blue, DAPI) and fibrillar actin (red, rhodamine phalloidin). (F) The porous (left) and non-porous (right) HA graft materials form a moldable putty when hydrated with bone marrow aspirate.

\subsection{Surgical Protocol}

The animal surgical protocol for this study was reviewed and approved by the Ibex Preclinical Research Institutional Animal Care and Use Committee (IACUC). The protocol number was C12611-Ibex-09-10 and approved on 10 April 2013. All animal work, histology, and radiographic analysis were completed by WuXi AppTec (St. Paul, MN, USA) unless otherwise stated. A total of 30 adult, male, New Zealand white rabbits were bilaterally implanted with grafts of porous and non-porous HA granules into a critical size defect created on the femoral condyle. First, bone marrow aspirate was harvested from the iliac crests of each animal (2 cc per rabbit). The porous and non-porous HA grafts were separately mixed with the autologous bone marrow aspirate (BMA) of each animal 
prior to implantation by combining $0.5 \mathrm{cc}$ BMA with $0.5 \mathrm{cc}$ porous or non-porous HA granules (1:1 ratio by volume), respectively. Each biomaterial contained a gelatin carrier that dissolved when wetted with BMA and formed a viscous gel around each HA particle. The resulting putty was loaded into $1 \mathrm{~mL}$ syringes, with the distal tip removed in order to form bone graft logs for implantation. The excess BMA was transported to the laboratory (Celling Biosciences, Austin, TX, USA) for cell analysis. Two drill defects (approximately $6 \mathrm{~mm}$ in diameter and $8-10 \mathrm{~mm}$ in length) were created in each animal—one in each femoral condyle-and were filled with porous HA graft on the left side and non-porous HA graft on the right side (Figure 2). Approximately $0.25 \mathrm{~cm}^{3}$ of hydrated graft material was implanted in each defect by pushing the putty out of the $1 \mathrm{~mL}$ syringe. Each animal received sufficient analgesic (butophanol $0.5-1.0 \mathrm{mg} / \mathrm{kg}$ ) injection prior to and after the surgery. The animals also received a fentanyl transdermal patch on the skin for additional analgesia up to 3 days. Ten animals were implanted per time point $(4,8$, and 13 weeks).

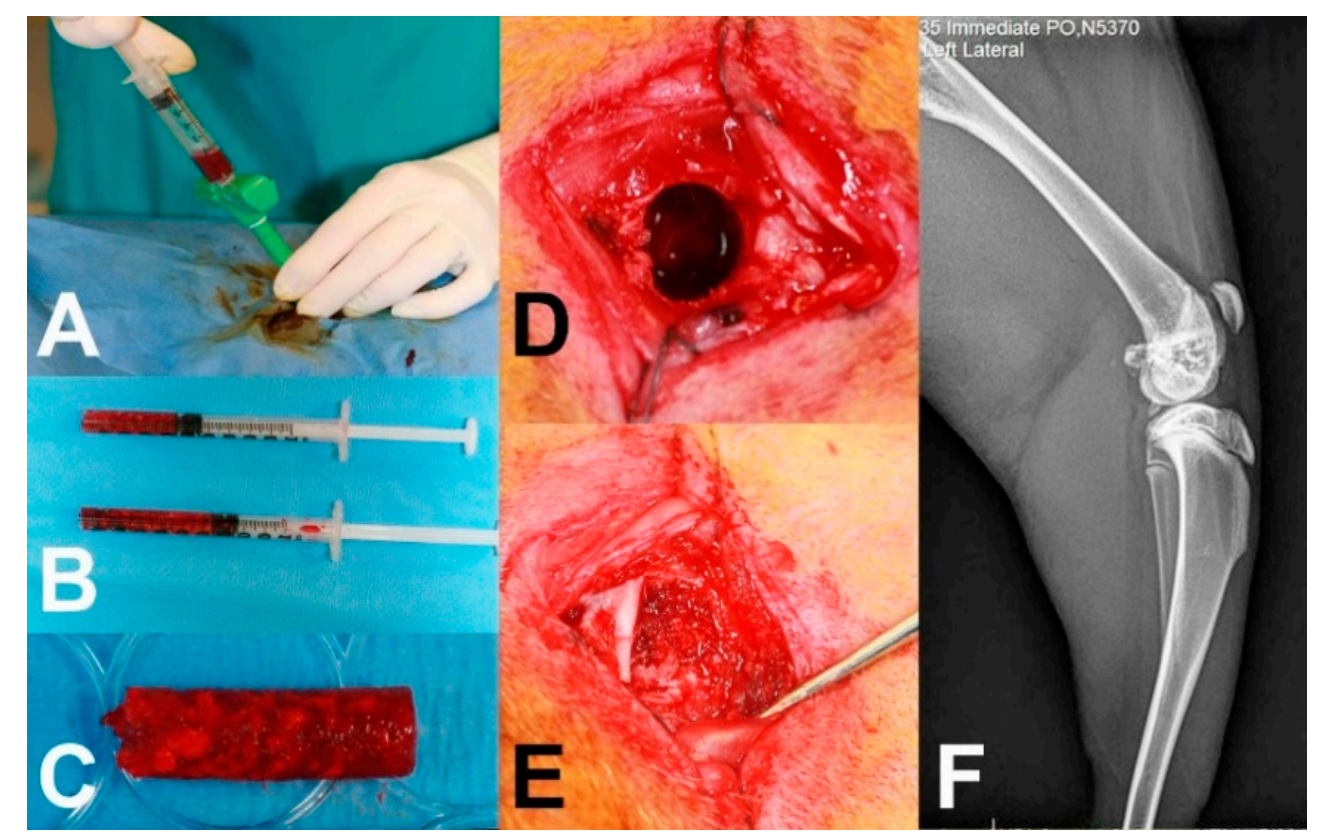

Figure 2. At the onset of surgery, bone marrow aspirate was drawn from the iliac crest of each rabbit (A) and mixed with porous or non-porous hydroxyapatite granule at 1:1 ratio by volume in a $1 \mathrm{~mL}$ syringe $(\mathbf{B})$ to form implantable cylinders $($ C). $6 \mathrm{~mm} \times 8 \mathrm{~mm}$ (diameter $\times$ length) defects were created bilaterally in the femoral chondyles (D) and packed with the graft materials (E), which were observed radiographically $(\mathbf{F})$.

Radiographs were collected post-operatively and at termination for each animal. At necropsy, 4,8 , or 13 weeks after implantation, the randomly assigned 10 animals were euthanized, and gross observations of the implant sites were observed and recorded. Implantation sites were excised and placed in $10 \%$ neutral buffered formalin for fixation. Radiographic microCT analysis was performed on the 8- and 13-week animals (Numira Biosciences, Inc., Salt Lake City, UT, USA). Histological preparation was done immediately after animal sacrifice for the 4-week samples, and following microCT analysis on the 8- and 13-week samples. Standard techniques were used to prepare slides for histological analysis. This included decalcification, paraffin embedding, microtome sectioning, and staining. Two slides were prepared from each defect, one at the central level of the drill defect and one from the interface with original bone. The slides were stained with hematoxylin/eosin (H\&E). Each section was analyzed by a pathologist for local tissue reaction, following the ISO 10993-6 guidelines-first by an independent pathologist (WuXi ApTec, St. Paul, MN, USA), and reviewed by a second independent pathologist (NAMSA, Minneapolis, MN, USA). 


\subsection{Cellular Analysis of Bone Marrow Aspirate}

BMA samples from late harvest-time-point animals ( 8 and 13 weeks) were transported to the laboratory in $5{ }^{\circ} \mathrm{C}$ temperature-controlled packs and analyzed within $24 \mathrm{~h}$ of aspiration. Total nucleated cell (TNC) counts and viability were quantified by NucleoCounter (New Brunswick, Enfield, CT, Canada) after diluting the $1 \mathrm{~mL}$ BMA aliquot with $9 \mathrm{~mL}$ phosphate-buffered saline (PBS) and $2 \%$ fetal bovine serum (FBS, HyClone human mesenchymal stem cell grade, Logan, UT, USA). The frequency of colony-forming unit-fibroblast (CFU-F), a marker for mesenchymal progenitor cells, was determined after the density-gradient depletion of red blood cells (Ficoll-Paque, GE Healthcare, Piscataway, NJ, USA), after which nucleated cells where plated in serial dilutions in 12-well cell culture plates with medium (MSCM, ScienCell Research Laboratories, Carlsbad, CA, USA) containing 5\% FBS and 1\% antibiotic (penicillin/streptomycin, ScienCell Research Laboratories, Carlsbad, CA, USA) for 10 days in vitro ( $n=3$ per dilution). Complete media changes were performed on days 4 and 7 . The average CFU-F concentration in the BMA was determined by multiplying TNC concentration (TNC/mL) by CFU-F frequency (CFU-F/TNC). Excess composite graft (BMA + porous HA granules) samples were analyzed by cell viability after $24 \mathrm{~h}$ by NucleoCounter after diluting the graft in PBS. Individual granules of non-implanted grafts were imaged by washing and fixing cells with $2 \%$ formalin and performing confocal microscopy after staining actin filaments with FITC-phalloidin (Invitrogen, $10 \mathrm{mg} / \mathrm{mL}$ ) and rhodamine anti-vinculin/DAPI (Invitrogen, $10 \mu \mathrm{g} / \mathrm{mL}$ ) staining, for cell membrane focal adhesions and nuclei, respectively (Figure 1E).

\subsection{MicroCT, Histological and Radiographic Analysis}

After 4, 8, and 13 weeks, 10 animals per time point were euthanized and a radiograph of each implant per animal was obtained (dorsal-ventral and lateral views). The bone implant sites were exposed and gross observations for local tissue reactions recorded, as per the ISO 10993-6 guidelines. The bone implant sites were placed in $10 \%$ neutral buffered formalin for fixation. Each formalin-fixed bone implant site from the 8- and 13-week time points, prior to histopathological analysis, was sent to Numira for microCT analysis of new bone formed and residual graft material in and adjacent to the defect volume. All samples were scanned on a high-resolution microCT scanner ( $\mu \mathrm{CT} 40$, ScanCo Medical, Zurich, $\mathrm{CH}$, Switzerland). The microCT images were analyzed using Numira Biosciences' VHLab. Analysis included determination of bone volume, total defect volume, remaining implant (HA) volume, and bone density. Each explanted bone sample was processed by standard histological techniques, including decalcification, paraffin embedding, microtome sectioning, and staining, as described in the previous section.

\subsection{Statistical Analysis}

All measurements are represented as the mean \pm standard error $(n=10$, unless otherwise noted). For statistical analysis, the means were compared using a one-way analysis of variance (ANOVA) for each variable combination using JMP 9 statistical software (SAS, Cary, NC, USA). Data were tested on a normal distribution and a $p$-value $<0.05$ was considered to indicate significance, in which statistical differences were determined using Tukey's HSD test, with calculations performed using Microsoft Excel.

\section{Results}

\subsection{Cellular Analysis of Bone Marrow Aspirate}

The twenty rabbits bone marrow aspirate samples contained an average of $3.20 \times 10^{7} / \mathrm{mL}$ $\mathrm{TNC} / \mathrm{mL}$ and $2710 \mathrm{CFU}-\mathrm{F} / \mathrm{mL}$. The average CFU-F frequency among nucleated cells was $0.0085 \%$. There were no statistically significant differences in TNC $\left(3.23 \times 10^{7} / \mathrm{mL}\right.$ vs. $\left.3.18 \times 10^{7} / \mathrm{mL}\right)$ or CFU-F concentration $\left(2.49 \times 10^{3} / \mathrm{mL}\right.$ vs. $\left.2.94 \times 10^{3} / \mathrm{mL}\right)$ between the 8 - and 13-week animal groups, respectively (Table 1 ). 
Table 1. Average total nucleated cell (TNC) and colony-forming unit-fibroblast (CFU-F) concentrations, and scaffold and bone characterization by MicroCT for porous and non-porous hydroxyapatite implants at 8 - and 13-week harvest time points ( $n=10$ per material per time point).

\begin{tabular}{|c|c|c|c|c|c|c|}
\hline Data by Time Point: & \multicolumn{3}{|c|}{ 8-Week Groups $(n=10)$} & \multicolumn{3}{|c|}{ 13-Week Groups $(n=10)$} \\
\hline Average TNC/mL & \multirow{2}{*}{\multicolumn{3}{|c|}{$\begin{array}{c}3.23 \times 10^{7} \pm 5.44 \times 10^{6} \\
2486 \pm 933\end{array}$}} & \multirow{2}{*}{\multicolumn{3}{|c|}{$\begin{array}{c}3.18 \times 10^{7} \pm 3.41 \times 10^{6} \\
2935 \pm 488\end{array}$}} \\
\hline Average CFU-F/mL & & & & & & \\
\hline & Porous & Non-porous & $p$-value & Porous & Non-porous & $p$-value \\
\hline Residual Scaffold Vol. $\left(\mathrm{mm}^{3}\right)$ & 22.62 & 54.11 & $<0.001$ & 14.59 & 42.50 & $<0.001$ \\
\hline Bone Vol. (BV) $\left(\mathrm{mm}^{3}\right)$ & 22.25 & 15.87 & 0.009 & 29.63 & 16.16 & $<0.001$ \\
\hline Bone Vol./Total Vol. & 0.23 & 0.16 & 0.009 & 0.31 & 0.17 & $<0.001$ \\
\hline Connectivity Density $\left(1 / \mathrm{mm}^{3}\right)$ & 28.45 & 8.73 & $<0.001$ & 40.40 & 12.84 & $<0.001$ \\
\hline Trabecular Thickness (mm) & 0.18 & 0.15 & 0.004 & 0.19 & 0.15 & $<0.001$ \\
\hline Bone Surface Area $\left(\mathrm{mm}^{2}\right)$ & 446.02 & 410.81 & 0.384 & 576.81 & 442.76 & 0.003 \\
\hline Mean Bone Density $\left(\mathrm{mgHA} / \mathrm{cm}^{3}\right)$ & 730.84 & 615.17 & $<0.001$ & 771.76 & 644.94 & $<0.001$ \\
\hline \multirow[t]{2}{*}{ Data by Scaffold Type: } & \multicolumn{3}{|c|}{ Porous HA $(n=10)$} & \multicolumn{3}{|c|}{ Non-porous HA $(n=10)$} \\
\hline & 8 weeks & 13 weeks & $p$-value & 8 weeks & 13 weeks & $p$-value \\
\hline Residual Scaffold Vol. $\left(\mathrm{mm}^{3}\right)$ & 22.62 & 14.59 & 0.014 & 54.11 & 42.50 & 0.049 \\
\hline Bone Vol. (BV) $\left(\mathrm{mm}^{3}\right)$ & 22.25 & 29.63 & 0.003 & 15.87 & 16.16 & 0.901 \\
\hline Bone Vol./Total Vol. & 0.23 & 0.31 & 0.003 & 0.16 & 0.17 & 0.899 \\
\hline Connectivity Density $\left(1 / \mathrm{mm}^{3}\right)$ & 28.45 & 40.40 & 0.010 & 8.73 & 12.84 & 0.078 \\
\hline Trabecular Thickness (mm) & 0.18 & 0.19 & 0.207 & 0.15 & 0.15 & 0.884 \\
\hline Bone Surface Area $\left(\mathrm{mm}^{2}\right)$ & 446.02 & 576.81 & 0.003 & 410.81 & 442.76 & 0.447 \\
\hline Mean Bone Density $\left(\mathrm{mgHA} / \mathrm{cm}^{3}\right)$ & 730.84 & 771.76 & 0.016 & 615.17 & 644.94 & 0.027 \\
\hline
\end{tabular}

\subsection{Bone Formation and Scaffold Degradation}

Histology reports indicated that the local tissue reaction to both the porous and non-porous materials was similar. All specimen showed implanted material surrounded and divided by new bone formation (indicated by presence of cartilage, woven bone, lamellar bone, and bone marrow). An increase in neovascularization as compared to non-treated bone was also observed, a result consistent with healing. Furthermore, the amount of woven bone decreased between 4 and 8 weeks to 13 weeks in both porous and non-porous samples, indicating mature bone development and remodeling. The pathologist concluded that the porous material had faster resorption and increased new bone formation within the implant sites, as compared to the non-porous material. At 8 weeks, approximately $25-50 \%$ of the HA remained, with no evidence of tissue toxicity in either group.

New bone formation and residual scaffold volume were measured by microCT at 8 and 13 weeks after implantation. Bone and scaffold characterization were performed by microCT for the entire volume of the defect (Figure 3). New bone and residual scaffold material were independently identified and measured within the region of interest by utilizing the difference in opacity between the newly-formed bone and the scaffold materials within the easily identifiable defect geometry. All data are summarized in Table 1 and reported as a comparison of porous and non-porous HA at 8 and 13 weeks, as well as a temporal comparison by material at 8 vs. 13 weeks. There were statistically significant increases in bone volume, bone fill percentage (bone volume/total volume), connectivity density, trabecular thickness, and mean bone density with porous granules as compared to the non-porous at the 8- and 13-week time points, as well as bone surface area at 13 weeks. The average rate of bone regeneration and volume of new bone for each animal is graphically illustrated in Figure 4. There were statistically significant differences between the materials in new bone volume at both time points $(p<0.01)$. The increase of new bone for each material between the 8- and 13-week time points was only significant for porous HA $(p<0.005)$ and corresponded to resorption of the implant material. Bone volume after implantation was statistically equivalent between 8 and 13 weeks for non-porous HA. Resorption of scaffold materials between the two time points was significant for both materials, with $35 \%$ less volume in porous scaffolds $(p<0.02)$ and $21 \%$ less volume in non-porous scaffolds $(p<0.05)$. 


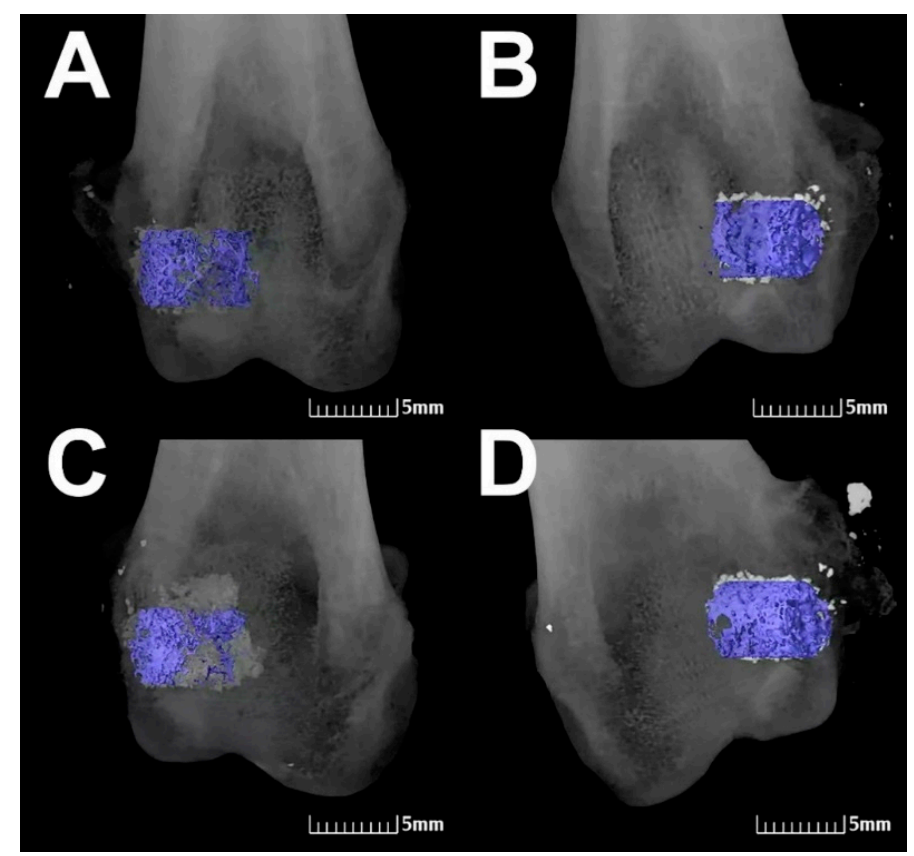

Figure 3. Representative MicroCT images at 8 weeks post-implantation of autologous bone marrow aspirate with non-porous (A) or porous (B) HA microparticles. Similar images taken at 13 weeks post-implantation for non-porous (C) and porous (D) HA microparticles. New bone formation (purple) and residual scaffold material (white, light gray) were calculated as a total volume and percentage of the original defect volume.

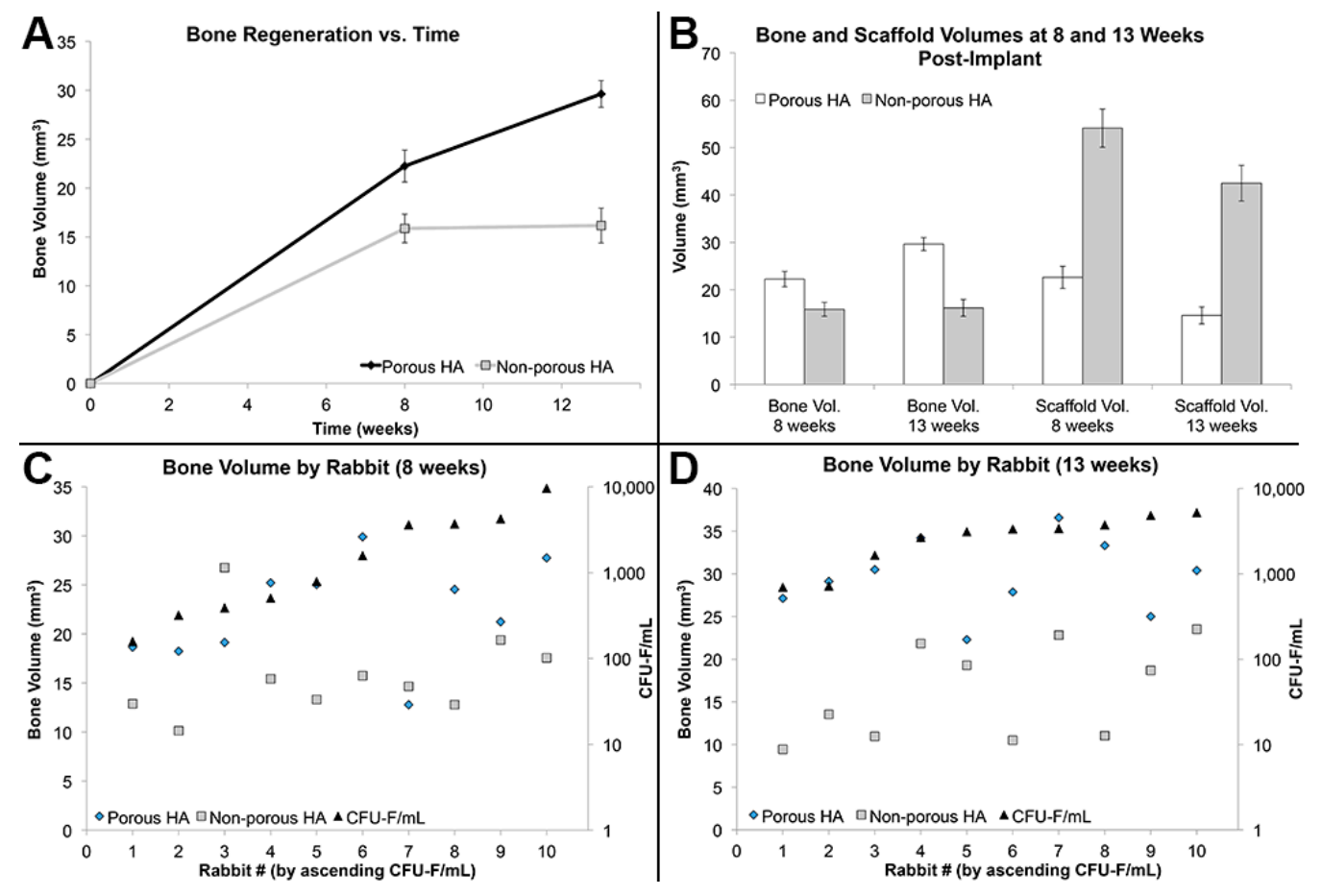

Figure 4. (A) Average bone regeneration versus time for porous (black) and non-porous (gray) hydroxyapatite (HA) granules through 13 weeks in vivo, with significant differences at both time points $(p<0.01)$ and improvement with porous HA between 8 and 13 weeks $(p>0.005)$; (B) new bone and remaining scaffold volume at 8 and 13 weeks for each material with significant decreases in residual scaffold for all scaffolds $(p<0.05)$. New bone volume regenerated by porous and non-porous HA and corresponding colony forming units-fibroblast (CFU-F or MSC) concentration by rabbits at 8 (C) and 13 weeks (D) indicates improved function of non-porous scaffolds with increasing CFU-F/mL. 


\subsection{Effect of MSC Concentration on Bone Formation}

The quantified bone growth values (microCT) were compared to MSC (CFU-F) concentrations for each animal at both time points (Figure $4 \mathrm{C}, \mathrm{D}$ ). More bone volume was generated using porous HA granules in $8 / 10$ animals at 8 weeks and 10/10 animals at 13 weeks. There was a positive correlation between MSC concentration and new bone for both materials and at both time points, which was more so with non-porous HA. Similarly, the difference in new bone volume between the materials (i.e., Bone Volume ${ }^{(\text {Porous HA) }}$-Bone Volume ${ }^{(\text {Non-Porous HA) }}$ ) was compared with CFU-F/mL for each animal and showed a negative correlation $\left(R^{2}=0.25\right)$, indicating that greater MSC content may compensate for intrinsic deficiencies in the osteoinductivity of non-porous scaffolds.

\section{Discussion}

Porous and non-porous HA granules, combined with autologous BMA, was able to successfully regenerate bone in all subjects. However, porous HA regenerated a significantly greater amount of bone at 8 - and 13 -week time points ( $44 \%$ and $82 \%$ more, respectively). It is generally understood that greater porosity of a scaffold is advantageous in tissue engineering and that material properties must be considered based on the clinical application [20-22]. In the present study, both bone void fillers had similar features, but key differences were the amount of surface area available for cell retention and the total and interconnected porosity for tissue and vascular infiltration. Previously, monolithic porous HA scaffolds were synthesized using similar methods and demonstrated bone growth and vascular infiltration, but were custom-made based on pre-determined defect dimensions $[4,5,23]$. These approaches achieved bone regeneration in a non-critically-sized canine mandibular defect ( $36.4 \%$ volume) and a critically-sized rabbit radial defect $\left(40 \mathrm{~mm}^{3}\right.$ new bone). By utilizing a microparticle-based formulation, it would be possible to capitalize on the osteogenic properties of the scaffold material, though it should be done in a moldable formulation. This approach would not only increase clinical ease of use in geometrically complex defects, but also the total surface area of the materials, which may alter degradation rates allowing for faster implant incorporation [24]. Greater porosity and surface area would be created by replacing a single porous scaffold with hundreds of smaller $(<2 \mathrm{~mm})$ porous scaffolds. Non-porous granules were found to be able to mold and pack the defects but encompassed significantly less surface area and porosity.

The significant differences in residual scaffold volume between porous and non-porous HA is not surprising, considering the differences in the porosity of the materials. The increased rate of material resorption in porous HA is hypothesized to be due to its greater surface area for contacting biological fluids and tissue that could increase the mechanical stress on its thin struts, leading to physical degradation of the material and potentially accelerating biological or osteoclastic breakdown of the HA. It is also possible that faster osteoinduction within and around the scaffolds accelerated the natural remodeling and turnover of the porous material. No correlation between TNC or MSC concentrations in the graft preparations and the degradation rates of the implants was observed.

The present study utilized autologous BMA as a source of progenitor cells to be co-implanted with the scaffolds. The choice of non-cultured, autologous cells was made for two reasons. Firstly, the use of autologous cells at the point-of-care is safe (minimal risk of contamination, prevents possible immune based reactions to allogeneic cells or culture medium proteins), and is easily translatable based on regulatory statutes. Secondly, other studies have demonstrated the increased potency, on a per-cell basis, of fresh or non-cultured bone marrow stromal cells compared to culture-expanded cell lines [25,26]. The contribution of MSCs had an apparent positive effect on bone formation. This was seen for both materials, but more so for the non-porous HA particles. The more interesting result was the reduction in differences between the porous and non-porous HA new bone volumes with increasing mesenchymal cell content (Figure 4D). As CFU-F/mL increased, the amount of bone generated in non-porous HA implants increased more than in porous HA grafts. This effect may be elucidated using the value determined by Hernigou et al. to be the critical concentration of MSCs for healing non-union fractures (1500 CFU-F/mL) [17]. At 13 weeks, rabbits with $>1500$ CFU-F/mL regenerated 
an average of $30.0 \mathrm{~mm}^{3}$ (porous) and $17.3 \mathrm{~mm}^{3}$ (non-porous) new bone, compared to rabbits with $<1500 \mathrm{CFU}-\mathrm{F} / \mathrm{mL}$ that regenerated $28.1 \mathrm{~mm}^{3}$ (porous) and $11.5 \mathrm{~mm}^{3}$ (non-porous) new bone $(p<0.05$ ). Thus, it would seem that bone growth on non-porous scaffolding material was more dependent on cell concentration as compared to a porous material.

It is unknown what contribution was made by hematopoietic, endothelial, platelets, and other cell types comprised in BMA that are not present in a culture-expanded, homogeneous population of MSCs. Typically, nucleated cell concentration correlated with CFU-F $\left(R^{2}=0.69\right)$, so it is probable that all cell types were enriched proportionally to CFU-F (i.e., animals with greater MSC concentrations likely had greater HSC concentrations as well). Further studies are warranted with phenotypic characterization of cell populations within non-cultured bone marrow aspirate and the relationship with bone formation and scaffold remodeling. The contribution of growth factors delivered by platelets and soluble in plasma that are not present in culture-expanded cell preparations should also be considered [27-29].

\section{Conclusions}

Treatment of critically-sized skeletal defects requires optimization of scaffold materials, cellular populations, and protein inclusions. The objectives of this investigation were to tandem the benefits of porosity (common in large tissue engineering scaffolds) with the handling characteristics and ability to pack small irregularly-shaped defects with granular putties and to identify any effects of mesenchymal cell concentration on bone formation and scaffold resorption. Porous HA microparticles were explored to maximize the porosity and surface area of a recognized osteoinductive substrate. Porous HA regenerated more bone than non-porous HA in $80 \%$ of rabbits at 8 weeks and $100 \%$ of rabbits at 13 weeks. The additional porosity resulted in significant increases in new bone formation and osteoinductively compensated for grafts with low mesenchymal and nucleated cell counts. The benefits from the greater MSC concentration was reaped most by the non-porous HA at 13 weeks post-implantation.

Author Contributions: E.R.D. and M.B.M. conceived and designed the experiments; E.R.D., R.K.S., and M.A.S. performed the experiments; E.R.D. and M.B.M. analyzed the data; E.R.D. and R.K.S. provided full materials characterization; E.R.D. and M.B.M. wrote the paper.

Funding: This research received no external funding.

Acknowledgments: We acknowledge the contributions of Daniel Oh in the preparation of porous HA granules. We acknowledge the support of Jizong Gao and John Rossman for sample processing and interpretive analysis of in vitro and in vivo outcomes.

Conflicts of Interest: The authors declare no conflict of interest.

\section{References}

1. Silber, J.S.; Anderson, D.G.; Daffner, S.D.; Brislin, B.T.; Leland, J.M.; Hilibrand, A.S.; Vaccaro, A.R.; Albert, T.J. Donor site morbidity after anterior iliac crest bone harvest for single-level anterior cervical discectomy and fusion. Spine 2003, 28, 134-139. [CrossRef] [PubMed]

2. Heise, U.; Osborn, J.F.; Dawe, F. Hydroxyapatite ceramic as a bone substitute. Int. Orthop. 1990, 14, 329-338. [CrossRef] [PubMed]

3. Oonishi, H. Orthopaedic applications of hydroxyapatite. Biomaterials 1991, 12, 171-178. [CrossRef]

4. Appleford, M.R.; Oh, S.; Oh, N.; Ong, J.L. In vivo study on hydroxyapatite scaffolds with trabecular architecture for bone repair. J. Biomed. Mater. Res. Part A 2009, 89, 1019-1027. [CrossRef] [PubMed]

5. Son, J.S.; Appleford, M.; Ong, J.L.; Wenke, J.C.; Kim, J.M.; Choi, S.H.; Oh, D.S. Porous hydroxyapatite scaffold with three-dimensional localized drug delivery system using biodegradable microspheres. J. Control. Release 2011, 153, 133-140. [CrossRef] [PubMed]

6. Laurencin, C.T.; Ambrosio, A.M.A.; Borden, M.D.; Cooper, J.A., Jr. Tissue engineering: Orthopedic applications. Annu. Rev. Biomed. Eng. 1999, 1, 19-46. [CrossRef] [PubMed] 
7. Kuboki, Y.; Takita, H.; Kobayashi, D.; Tsuruga, E.; Inoue, M.; Murata, M.; Nagai, N.; Dohi, Y.; Ohgushi, H. BMP-induced osteogenesis on the surface of hydroxyapatite with geometrically feasible and nonfeasible structures: Topology of osteogenesis. J. Biomed. Mater. Res. 1998, 39, 190-199. [CrossRef]

8. Chang, B.S.; Hong, K.S.; Youn, H.J.; Ryu, H.S.; Chung, S.S.; Park, K.W. Osteoconduction at porous hydroxyapatite with various pore configurations. Biomaterials 2000, 21, 1291-1298. [CrossRef]

9. Karageorgiou, V.; Kaplan, D. Porosity of 3D biomaterial scaffolds and osteogenesis. Biomaterials 2005, 26, 5474-5491. [CrossRef] [PubMed]

10. Woodard, J.R.; Hilldore, A.J.; Lan, S.K.; Park, C.J.; Morgan, A.W.; Eurell, J.A.C.; Clark, S.G.; Wheeler, M.B.; Jamison, R.D.; Johnson, A.J.W. The mechanical properties and osteoconductivity of hydroxyapatite bone scaffolds with multi-scale porosity. Biomaterials 2007, 28, 45-54. [CrossRef] [PubMed]

11. Den Boer, F.C.; Wippermann, B.W.; Blokhuis, T.J.; Patka, P.; Bakker, F.C.; Henk, J.T.M. Healing of segmental bone defects with granular porous hydroxyapatite augmented with recombinant human osteogenic protein-1 or autologous bone marrow. J. Orthop. Res. 2003, 21, 521-528. [CrossRef]

12. Gan, Y.; Dai, K.; Zhang, P.; Tang, T.; Zhu, Z.; Lu, J. The clinical use of enriched bone marrow stem cells combined with porous beta-tricalcium phosphate in posterior spinal fusion. Biomaterials 2008, 29, 3973-3982. [CrossRef] [PubMed]

13. Kubo, T.; Doi, K.; Hayashi, K.; Morita, K.; Matsuura, A.; Teixeira, E.R.; Akagawa, Y. Comparative evaluation of bone regeneration using spherical and irregularly shaped granules of interconnected porous hydroxylapatite. A beagle dog study. J. Prosthodont. Res. 2011, 55, 104-109. [CrossRef] [PubMed]

14. Murphy, M.B.; Blashki, D.; Buchanan, R.M.; Tasciotti, E. Engineering a better way to heal broken bones. Chem. Eng. Prog. 2010, 106, 37-43.

15. Murphy, M.B.; Moncivais, K.; Caplan, A.I. Mesenchymal stem cells: Environmentally responsive therapeutics for regenerative medicine. Exp. Mol. Med. 2013, 45, e54. [CrossRef] [PubMed]

16. Murphy, M.B.; Suzuki, R.K.; Sand, T.T.; Chaput, C.D.; Gregory, C.A. Short Term Culture of Human Mesenchymal Stem Cells with Commercial Osteoconductive Carriers Provides Unique Insights into Biocompatibility. J. Clin. Med. 2013, 2, 49-66. [CrossRef] [PubMed]

17. Hernigou, P.; Poignard, A.; Beaujean, F.; Rouard, H. Percutaneous Autologous Bone-Marrow Grafting for Nonunions. J. Bone Jt. Surg. Incorp. 2005, 87, 1430-1437. [CrossRef]

18. Hernigou, P.; Daltro, G.; Filippini, P.; Mukasa, M.M.; Manicom, O. Percutaneous implantation of autologous bone marrow osteoprogenitor cells as treatment of bone avascular necrosis related to sickle cell disease. Open Orthop. J. 2008, 2, 62-65. [CrossRef] [PubMed]

19. Hernigou, P.; Lachaniette, C.H.F.; Delambre, J.; Zilber, S.; Duffiet, P.; Chevallier, N.; Rouard, H. Biologic augmentation of rotator cuff repair with mesenchymal stem cells during arthroscopy improves healing and prevents further tears: A case-controlled study. Int. Orthop. 2014, 38, 1811-1818. [CrossRef] [PubMed]

20. Khademhosseini, A.; Langer, R.; Borenstein, J.; Vacanti, J.P. Microscale technologies for tissue engineering and biology. Proc. Natl. Acad. Sci. USA 2006, 103, 2480-2487. [CrossRef] [PubMed]

21. Dawson, E.; Mapili, G.; Erickson, K.; Taqvi, S.; Roy, K. Biomaterials for stem cell differentiation. Adv. Drug Deliv. Rev. 2008, 60, 215-228. [CrossRef] [PubMed]

22. Murphy, M.B.; Blashki, D.; Buchanan, R.M.; Fan, D.; De Rosa, E.; Shah, R.N.; Stupp, S.I.; Weiner, B.K.; Simmons, P.J.; Ferrari, M.; et al. Multi-Composite Bioactive Osteogenic Sponges Featuring Mesenchymal Stem Cells, Platelet-Rich Plasma, Nanoporous Silicon Enclosures, and Peptide Amphiphiles for Rapid Bone Regeneration. J. Funct. Biomater. 2011, 2, 39-66. [CrossRef] [PubMed]

23. Guda, T.; Walker, J.A.; Pollot, B.E.; Appleford, M.R.; Oh, S.; Ong, J.L.; Wenke, J.C. In vivo performance of bilayer hydroxyapatite scaffolds for bone tissue regeneration in the rabbit radius. J. Mater. Sci. Mater. Med. 2011, 22, 647-656. [CrossRef] [PubMed]

24. Bohner, M.; Baumgart, F. Theoretical model to determine the effects of geometrical factors on the resorption of calcium phosphate bone substitutes. Biomaterials 2004, 25, 3569-3582. [CrossRef] [PubMed]

25. Kretlow, J.D.; Jin, Y.Q.; Liu, W.; Zhang, W.J.; Hong, T.H.; Zhou, G.; Baggett, L.S.; Mikos, A.G.; Cao, Y. Donor age and cell passage affects differentiation potential of murine bone marrow-derived stem cells. BMA Cell Biol. 2008, 9, 60. [CrossRef] [PubMed]

26. Kretlow, J.D.; Spicer, P.P.; Jansen, J.A.; Vacanti, C.A.; Kasper, F.K.; Mikos, A.G. Uncultured Marrow Mononuclear Cells Delivered Rat Cranial Defects. Tissue Eng. Part A 2010, 16, 3555-3568. [CrossRef] [PubMed] 
27. Murphy, M.B.; Blashki, D.; Buchanan, R.M.; Yazdi, I.K.; Ferrari, M.; Simmons, P.J.; Tasciotti, E. Adult and umbilical cord blood-derived platelet-rich plasma for mesenchymal stem cell proliferation, chemotaxis, and cryo-preservation. Biomaterials 2012, 33, 5308-5316. [CrossRef] [PubMed]

28. Weibrich, G.; Hansen, T.; Kleis, W.; Buch, R.; Hitzler, W.E. Effect of platelet concentration in platelet-rich plasma on peri-implant bone regeneration. Bone 2004, 34, 665-671. [CrossRef] [PubMed]

29. Sarkar, M.R.; Augat, P.; Shefelbine, S.J.; Schorlemmer, S.; Huber-Lang, M.; Claes, L.; Kinzl, L.; Ignatius, A. Bone formation in a long bone defect model using a platelet-rich plasma-loaded collagen scaffold. Biomaterials 2006, 27, 1817-1823. [CrossRef] [PubMed]

(C) 2018 by the authors. Licensee MDPI, Basel, Switzerland. This article is an open access article distributed under the terms and conditions of the Creative Commons Attribution (CC BY) license (http://creativecommons.org/licenses/by/4.0/). 